Parte I 



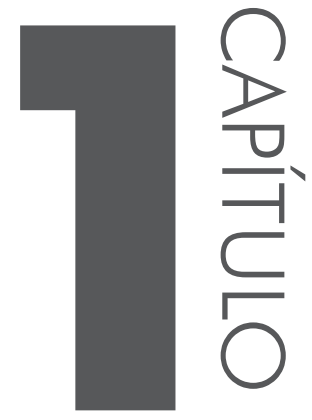

\section{A COR DA TERNURA: $O$ DESAFIO DE SER PROFESSOR NEGRO NA EDUCAC̣ÃO ATUAL DO SUDESTE GOIANO}

Janaina Nayara de Paula ${ }^{1}$

Resumo: Este texto esboça uma proposta de pesquisa realizada no Programa de Pós-Graduação em História (PPGH) - Mestrado Profissional: História, Cultura e Formação de Professores da Universidade Federal de Goiás, Regional Catalão, cujos objetivos são: mostrar a condição de professores negros nas escolas do sudeste goiano, tentando, a partir desses espaços, problematizar a questão do racismo no Brasil, a relação entre o professor negro e a educação, bem como seu papel como educador nas escolas. Assim, a proposta metodológica analisa a importância da história dos professores negros no sudeste goiano, considerando suas histórias de vida, práticas didáticas e desafios encontrados na formação aca-

1 Universidade Federal de Goiás/Regional Catalão 
dêmica e atuação em sala de aula. Dessa forma, a discussão proposta pretende, também, enfrentar os embates no que diz respeito a ausência dessa reflexão nas escolas e na própria Academia, nas quais a população negra está sujeita à discriminação e ao racismo.

Palavras-chave: professores negros; racismo; discriminação.

Abstract: This paper outlines the proposal of a survey we conducted in PPGH - Professional Masters: History Culture and Teacher Training of the Federal University of Goiás Regional Catalão, whose objectives are: to show the condition of black teachers in Goiás southeastern schools, trying from these spaces, discuss the issue of racism in Brazil, the relationship between black and teacher education as well as their role as educators in schools. Thus, the methodological approach is to analyze the importance of black history teachers in Goiás southeast from their life stories, teaching practices and challenges encountered in academic and performance in the classroom. Thus, the discussion proposal also intends to address the conflicts in that regard the absence of this reflection in schools and even in the gym, where the black population is subject to discrimination and racism.

Keywords: black teachers, racism, discrimination.

\section{CONSIDERAC̣ÕES INICIAIS}

O presente artigo consiste de uma pesquisa ainda em desenvolvimento, realizada no PPGH - Mestrado Profissional, da UFG/Regional Catalão, cujos objetivos principais são: mostrar a condição de professores negros nas escolas públicas do sudeste goiano; problematizar a questão do racismo no Brasil; debater a relação entre o professor negro e a educação; discutir a escola como importante lócus de combate ao racismo; e problematizar a vida desses professores a partir de seus relatos. Nossa proposta é analisar a importância dos professores negros no sudeste goiano a partir de suas histórias de vida, de suas práticas educativas e dos desafios encontrados na formação acadêmica e atuação em sala de aula. A pesquisa possibilitará repensar também a escola como um espaço de cultura, moldado, em sua grande maioria, pelo desprezo à negritude, questão que que deve ser problematizada em suas práticas e representações (CHARTIER, 1988).

O trabalho se desenvolve levando em consideração os percursos que contribuíram para a construção da identidade desses professores, daí tem-se bibliografia e referencial teórico que discutem o racismo e a discriminação como situações que precisam ser tratadas historicamente, como se mostrará adiante.

Minhas motivações para a pesquisa são, inicialmente, de ordem pessoal, pois, em diversos momentos da minha vida, me deparei ou mesmo vivenciei situações e experiências racistas. Tanto na escola quanto fora dela, essas experiências são memórias permanentes que, hora ou outra, vêm à tona. A pesquisa, 
então se tornou um processo de problematização de tais memórias, não mais como marca da minha identidade pessoal, mas como marca da minha relação com o mundo e com o ensino. Esse trabalho tem vida e é narrado por alguém "do lado de cá", do lado de quem vive a vida de uma mulher negra, formada professora no Brasil.

Outra das minhas justificativas pessoais é sempre ter vivenciado diversos tipos de preconceitos, racismos, e discriminação racial ao longo de minha trajetória. $\mathrm{Na}$ infância tive vários embates com minha cor de pele, insatisfação com o cabelo, me sentia a criança mais feia da escola, não tinha amigos, mas somente uma amiga negra que partilhava comigo o desafio de ser negro em uma sociedade racista; vivemos juntas desde o berçário até concluirmos o ensino médio, e os embates por sermos negras eram os mesmos. Diariamente éramos chamadas de "macacas" "cabelim pixaim" "contonete sujo na cabeça" dentre outros apelidos, e permanecemos sempre juntas, mas ao fim do ensino médio, ela havia se convencido de que a universidade não era lugar para "pretos".

Certo dia minha professora da pré-escola me deu um livro intitulado $A$ cor da ternura, de Geni Guimarães, e me expressou com gestos e palavras o amor dela por mim. Lembro-me de ela ter me dito: "filha, você é linda, não tenha vergonha da sua cor. Olha pra tia branca e fica vermelha à toa, porque eu queria ser da sua cor. Você é um anjinho e é brilhante. Eu amo muito você e tenho orgulho de você". Eu a questionei se existia "anjinha pretinha" e ela me disse: "claro que sim, e os anjos negros são lindos como você”. Essas palavras me deram novo fôlego de vida, me senti importante, e desse dia em diante quis sempre ser motivo de orgulho para ela. Assim eu comecei a me amar, a gostar do meu cabelo e a me encontrar como ser humano, e por isso mesmo ingressei na universidade.

O livro, então, tornou-se uma referência em minha vida. A protagonista negra tinha orgulho da sua família, orgulho da sua parentela e orgulho da sua raça. No decorrer da trama, é notória a admiração da personagem pela mãe:

Ela era linda. Nunca me cansei de olhá-la. O dia todo arrastava os chinelos pela casa. Ia e vinha. [...] Quando me pegava no flagra, bebendo seus gestos, esboçava um riso calmo, curto. [...] Revivia o riso dela mil vezes e à noite deitava-me mais cedo para pensar no doce cheiro de terra e mãe. (GUIMARÃES, 1998, p. 13)

Nesse trecho, é perceptível uma mãe que tem sua rotina de trabalho, mas não é uma mãe escravizada, sofredora. Ou seja, a menina tinha em sua história outras pessoas negras que não remetiam àquele negro escravo, mas sim protagonistas da suas vida e história. E ainda que envolto por preconceitos no caminho, trata-se de um negro que consegue viver sua vida de forma independente, fazendo suas próprias escolhas. É assim, que, no fim da história, a menina se torna professora. 
Características como feiura, maldade, imoralidade, selvageria e passividade são características inferiorizantes que acompanharam as personagens negras durante muito tempo, mas, em seu livro, Geni Guimarães traz o contrário. A personagem principal realiza o seu sonho e o sonho de seus pais, tornando-se professora, rompendo com os paradigmas impostos pela sociedade e o destino de ser mucama, empregada doméstica ou prostituta. Na vida da protagonista de Geni, a transformação é mais que uma realização profissional, pois ser negra e professora em uma sociedade onde essas mulheres foram trazidas para serem amas de leite, para trabalharem como escravas ou para serem objeto sexual dos seus senhores, ser professora ultrapassava os limites da mera realização profissional, sendo uma questão social de quem acessa o que no mundo. O texto é uma representação literária do autoquestionamento de crianças negras em relação à sua cor de pele e posição social, uma vez que essas crianças já nascem com obstáculos a serem superados e crescem com sequelas, pois são, desde cedo, expostas à violência psicológica causada por atitudes racistas.

Outro fator que influenciou a realização dessa pesquisa é a história de minha tia, uma professora negra da cidade de Goiandira. Desde 1993 ela é professora concursada no município, tendo trabalhado com Educação de Jovens e Adultos até meados dos anos 2000. Depois, trabalhou com as séries iniciais do Ensino Fundamental ( $1^{\circ}$ e $2^{\circ}$ anos) até o ano de 2005 , e ministrou aulas como professora regente das turmas. Porém, em 2005, aconteceu um incidente, uma mãe foi até a diretoria da escola e afirmou que sua filha, que não tinha convívio com pessoas negras, tinha medo da professora, e diante dessa declaração, a professora - minha tia - foi afastada da sala de aula como professora regente e, desde então, lhe são atribuídas apenas aulas de reforço no período do tempo integral. Ou seja, há exatamente dez anos minha tia foi afastada da sala de aula a pedido de uma mãe racista que não admitia que a educação de sua filha fosse ministrada por uma negra. A coordenação usou vários outros argumentos e justificativas, mas o desfecho foi esse.

A história de minha tia é emblemática do tipo de preconceito que professores negros sofrem na sociedade. Uma professora negra na sociedade atual ainda é vista como um "bicho de sete cabeças", pois alguns alunos não querem ter essa professora; algumas mães não aceitam que seus filhos sejam ensinados por um negro e o sistema acaba acatando esse preconceito, dando ao mesmo "soluções diversas" que não constituem um enfrentamento claro da questão.

Diante do exposto minha tia se conformou com essa situação e hoje diz que este é o lugar no qual ela deveria estar, pois a regência não é para ela e sim para as "outras": subliminarmente, ela está dizendo que a regência da sala de aula é para as professoras brancas, apenas. Vale ressaltar que minha tia é graduada e pós graduada pela UFG, com inúmeras especializações, tendo capacidade e formação 
para atuar em sala de aula, mas sem aceitação social o respaldo institucional para o exercício de sua profissão. Ela sabe o que significa estar na escola como professora negra em uma sociedade racista.

Frente a essas questões, entendemos que, ao falarmos de racismo no Brasil, a primeira imagem que efetivamente vem à cabeça é a imagem dos negros. As pessoas tendem a fugir dessa discussão porque sabem do peso do preconceito contra o negro no Brasil, e percebe-se que o racismo é, muitas vezes, dissimulado, pois as pessoas têm preconceito de ter preconceito e negam constantemente a existência deste, como se fosse um problema inexistente.

Em O brasileiro, o racismo silencioso e a emancipação do afro-descendente, Ricardo Ferreira (2002) ressalta a importância de entendermos as formas pelas quais o preconceito é veiculado, sendo primordial buscarmos o entendimento sobre as condições históricas para o desenvolvimento do preconceito. O autor inicia seu texto destacando a argumentação de Nelson Rodrigues, quando este discute abertamente a questão da farsa brasileira, da qual muitos brasileiros se orgulham, que pelo fato de considerar que, no Brasil, vivemos uma "democracia racial" embora todos saibam da existência da discriminação e se eximam de discuti-la, o que, de certa forma, a legítima mais ainda. Ao falar sobre o assunto, as pessoas não admitem ser racistas, de forma que o preconceito sempre é do outro. Somos coniventes com um racismo silencioso, com termos que silenciam cada vez mais nosso preconceito, e diante das circunstâncias e do processo de desvalorização social, a pessoa negra tende a interiorizar a ideia da superioridade branca, dos brancos como classe dominante, desvalorizando o "mundo negro", tornando a afrodescendência o fator mais insignificante de suas vidas. Assim, começam a se apoiar no eurocentrismo como visão de mundo, tendo em vista os padrões de beleza derivados de uma estética branca e assumindo a sensação de não se encaixar em nenhum grupo social. "Experiências desconfirmatórias gradualmente podem provocar transformações. São processos conflitivos, pois questionam a maneira de ser e ver o mundo e tornam impossível ao negro negar a rejeição que sofre socialmente" (FERREIRRA, 2002, p. 77).

Ressalte-se que o racismo é corrente e recorrente no Brasil, onde a ideia de três raças ou democracia racial é, como diria Nelson Rodrigues, uma farsa. O mito de democracia racial gerou uma mentalidade distorcida nesses sujeitos e tem provocado na sociedade, de certa forma, o silenciamento, de maneira que é cada vez mais difícil aos professores entender quais são as motivações das discriminação sofridas e, principalmente, como reagir a isso e a partir de quais mecanismos, como a negação da existência do preconceito, a conformação ou ações que remetam à não percepção de sua existência. Nesse sentido, a pesquisa que realizo tem um papel social grande: problematizar a vida de professores negros nos seus contextos sociais e profissionais, e levar tal problemática para as escolas, seja por 
meio da divulgação da própria pesquisa ou de trabalhos e projetos específicos que mostrem o que é a vida desses professores no sudeste goiano.

Assim, um dos objetivos do trabalho também é problematizar o racismo como uma marca da cultura brasileira que tem interferido nos processos educativos, especialmente na relação entre professores negros e suas salas de aula. Escolhemos o contexto do sudeste goiano por ser este o espaço de realização da pesquisa de campo.

O referencial teórico metodológico adotado pauta-se na história cultural, tal como a mesma foi pensada por pesquisadores como Roger Chartier (2010) e Sandra Jatahy Pesavento (2004), que tomam a cultura não apenas como modo de vida, mas como modos e formas de representar essa vida em suas práticas e em seu cotidiano. Nesse sentido, também tomamos as fontes orais (ALBERTI, 1989), enquanto produção de história de vida para alcance dos sujeitos da pesquisa. Aliada a essas fontes, um trabalho de observação ativo será importante no processo de compreensão da cultura escolar na qual professores negros estão inseridos.

A história, portanto, trabalha com o passado e com o presente, com aquilo que os seres humanos produziram no passado e produzem no presente $(\mathrm{BLOCH}$, 2001). Nesse caso, o tempo deste trabalho é o tempo da memória, é o tempo das histórias que os testemunhos que recolhermos nos darão. É, de certa forma, um trabalho engajado no seu presente, pois o racismo é uma realidade atual.

Com isso, a proposta de trabalho final de nossa pesquisa é uma dissertação dividida em três tempos de discussão: o primeiro, que constituirá o primeiro capítulo da dissertação, intitulado "Democracia racial: mito ou fato"; o segundo, "A cor da ternura: e quando o professor é negro?"; e, por fim, "Professores negros, onde estão? Caminhos investigativos entre a história e a memória”, terceiro capítulo da dissertação.

\section{DEMOCRACIA RACIAL: MITO OU FATO?}

Neste momento, o objetivo é fazer algumas considerações sobre as relações raciais no Brasil e o racismo em si, tal como o mesmo pode ser pensado a partir do contexto de Goiás. A condição do professor negro em Goiás tem sido pouco debatida, e mesmo diante dessa escassez de estudos e reflexões, é notório que os trabalhos e pesquisas realizadas sobre a temática têm mostrado a existência da discriminação racial em todos os setores da vida social, o que explicita a desigualdade racial em Goiás.

No sudeste goiano, os professores vivem experiências desagradáveis de racismo e de discriminação que às vezes acontecem de forma silenciosa e, às vezes, de maneira explícita, tanto dentro quanto fora do âmbito escolar. No ambiente 
escolar ocorre estes atos discriminatórios, em sua maioria, como tentativa de inferiorizar os professores negros, designando a eles afazeres que, por vezes, não condizem com sua formação ou capacidade.

Entendemos que tais processos discriminatórios interferem de maneira significativa na autoestima do sujeito, levando-o a autonegação ou, até mesmo, à fuga dos espaços educativos e à tentativa de se ver livre das características comuns aos negros, instigando o desejo de se esconde. Ou seja, nossa pesquisa quer compreender como os professores negros têm levado sua vida profissional e como os ambientes escolares têm lidado com as diferenças raciais. Acreditamos que nosso estudo tenha grande importância social, pois coloca em destaque um problema real e que deve ser enfrentado por todos aqueles que fazem parte da comunidade escolar. O racismo não é só uma herança do nosso passado, o racismo faz parte do nosso dia a dia. Assim, esta parte do trabalho constará de uma revisão bibliográfica sobre as várias discussões históricas que foram realizadas no Brasil, principalmente por autores como Sidney Chaloub (2011), Joaquim Silvério Baia Horta (1994), Circe Bittencourt (1990), Jerry D’Ávila (2005), Patrícia Santana (2004), Maria Solange Ribeiro (2012), Florestan Fernandes (1965), Lee Anne Bell (2003), Guimes Rodrigues Filho e Cristina M. Ribeiro Perón (2011), Carlos Hasenbalg (1979), Carlos Hasenbalg: N. V. Silva (1988), Lilia Moritz Schwarcz (1993) e George Reid Andrews (1998), dentre tantos outros autores que, aqui, não temos espaço para tratar. Como pano de fundo dessa discussão bibliográfica está o magistral Casa grande e senzala, de Gylberto Freyre (1993), e os desdobramentos deste na discussão da democracia racial no Brasil. Nesse contexto, esta discussão servirá como suporte teórico para interpretação dos dados e análise das histórias de vida estudadas.

\section{A COR DA TERNURA: E QUANDO O PROFESSOR É NEGRO?}

Nesse momento se faz necessário apresentar as fontes que serão utilizadas no decorrer da pesquisa e as maneiras como que foram coletadas, sendo este um capítulo de exposição e análise.

No mês de setembro de 2015 foi finalizado o trabalho de campo, com recolha de material documental escrito nas escolas do sudeste goiano, reunindo as informações necessárias à pesquisa. Ainda em andamento, este processo tem mostrado que o racismo é uma realidade nas escolas e que, muitas vezes, suas vítimas são professores que vivem situações diversas, sendo obrigados a sair das salas de aula ou assumir funções que não correspondem à sua qualificação. Isso fornece um quadro mais claro de como se evidencia ou de como se camufla o racismo nas escolas do sudeste goiano, sendo pouco comum encontrarmos em nossas escolas 
professores e professoras negras, como fica evidente na Tabela 1, conforme levantamento em nove cidades do sudeste goiano, obtivemos os seguintes dados por amostragem.

Tabela 1. Levantamento de professores

\begin{tabular}{|c|c|c|c|c|}
\hline Cidade & Nome da Instituiç̣̃o & $\begin{array}{l}\text { Professores } \\
\text { Concursados }\end{array}$ & $\begin{array}{l}\text { Professores } \\
\text { Contratados }\end{array}$ & $\begin{array}{l}\text { Professores } \\
\text { Negros }\end{array}$ \\
\hline Anhanguera & 01. CMEI - Cantinho da Criança & 4 & 0 & 0 \\
\hline Anhanguera & $\begin{array}{l}\text { 02. Colégio Estadual Adelino } \\
\text { Antônio Gomide }\end{array}$ & 5 & 2 & 2 \\
\hline $\begin{array}{l}\text { Campo } \\
\text { Alegre }\end{array}$ & $\begin{array}{l}\text { 03. Colégio Estadual Major } \\
\text { Emídio }\end{array}$ & 17 & 11 & 2 \\
\hline Catalão & $\begin{array}{l}\text { 04. Associação Pestalozzi de } \\
\text { Catalão - Santa Clara }\end{array}$ & 23 & 0 & 0 \\
\hline Catalão & $\begin{array}{l}\text { 05. Colégio Estadual Abrahão } \\
\text { André }\end{array}$ & 32 & 3 & 1 \\
\hline Catalão & $\begin{array}{l}\text { 06. Colégio Estadual Anice } \\
\text { Cecilio Pedreiro }\end{array}$ & 36 & 8 & 2 \\
\hline Catalão & 07. Colégio Estadual Dona layá & 43 & 1 & 2 \\
\hline Catalão & $\begin{array}{l}\text { 08. Colégio Estadual Dr. David } \\
\text { Persicano }\end{array}$ & 39 & 5 & 3 \\
\hline Catalão & $\begin{array}{l}\text { 09. Colégio Estadual João Neto } \\
\text { de Campos }\end{array}$ & 48 & 6 & 0 \\
\hline Catalão & $\begin{array}{l}\text { 10. Colégio Estadual Maria das } \\
\text { Dores Campos }\end{array}$ & 42 & 8 & 2 \\
\hline Catalão & $\begin{array}{l}\text { 11. Colégio Estadual Rita } \\
\text { Paranhos Bretas }\end{array}$ & 20 & 1 & 0 \\
\hline Catalão & $\begin{array}{l}\text { 12. Colégio Nossa Senhora Mãe } \\
\text { de Deus }\end{array}$ & 23 & 4 & 0 \\
\hline Catalão & $\begin{array}{l}\text { 13. Colégio Polivalente Dr. } \\
\text { Tharsis Campos }\end{array}$ & 9 & 3 & 0 \\
\hline Catalão & $\begin{array}{l}\text { 14. Escola Estadual Joaquim de } \\
\text { Araújo e Silva }\end{array}$ & 11 & 5 & 0 \\
\hline Catalão & $\begin{array}{l}\text { 15. Escola Estadual Madre } \\
\text { Natividade Gorrochá Tegui }\end{array}$ & 17 & 6 & 1 \\
\hline Catalão & 16. Escola Estadual Prof. Zuzu & 29 & 2 & 1 \\
\hline
\end{tabular}


Tabela 1. Levantamento de professores (continuação)

\begin{tabular}{|c|c|c|c|c|}
\hline Cidade & Nome da Instituição & $\begin{array}{l}\text { Professores } \\
\text { Concursados }\end{array}$ & $\begin{array}{l}\text { Professores } \\
\text { Contratados }\end{array}$ & $\begin{array}{c}\text { Professores } \\
\text { Negros }\end{array}$ \\
\hline Catalão & $\begin{array}{l}\text { 17. Escola Estadual Wilson Elias } \\
\text { Jorge Democh }\end{array}$ & 15 & 1 & 0 \\
\hline Catalão & $\begin{array}{l}\text { 18. Instituto de Educação Matilde } \\
\text { Margon Vaz }\end{array}$ & 27 & 5 & 0 \\
\hline Catalão & $\begin{array}{l}\text { 19. Secretaria Municipal de } \\
\text { Educação }\end{array}$ & 529 & 16 & 1 \\
\hline Corumbaíba & 20. Colégio Estadual Simon Bolivar & 24 & 1 & 1 \\
\hline Corumbaíba & 21. Escola Comecinho de Vida & 45 & 0 & 4 \\
\hline Corumbaíba & $\begin{array}{l}\text { 22. Escola Estadual Osório } \\
\text { Martins Cardoso }\end{array}$ & 5 & 3 & 0 \\
\hline Corumbaíba & $\begin{array}{l}\text { 23. Escola Municipal Ascendino } \\
\text { Celestino da Silva }\end{array}$ & 22 & 0 & 2 \\
\hline Corumbaíba & $\begin{array}{l}\text { 24. Escola Municipal Couto de } \\
\text { Magalhães }\end{array}$ & 20 & 0 & 2 \\
\hline Corumbaíba & $\begin{array}{l}\text { 25. Escola Municipal Prof. Geani } \\
\text { Marcia dos Santos Lourenço }\end{array}$ & 9 & 0 & 0 \\
\hline Cumari & $\begin{array}{l}\text { 26. Colégio Estadual Castro } \\
\text { Alves }\end{array}$ & 13 & 2 & 0 \\
\hline Cumari & $\begin{array}{l}\text { 27. Colégio Estadual Getúlio } \\
\text { Evangelista da Rocha }\end{array}$ & 17 & 3 & 0 \\
\hline Cumari & $\begin{array}{l}\text { 28. Secretaria Municipal de } \\
\text { Educação e Cultura - Cumari }\end{array}$ & 20 & 0 & 1 \\
\hline Davinópolis & $\begin{array}{l}\text { 29. Colégio Estadual João } \\
\text { Bernardes de Assunção }\end{array}$ & 15 & 5 & 0 \\
\hline Goiandira & $\begin{array}{l}\text { 30. Colégio Estadual Dom } \\
\text { Emanuel }\end{array}$ & 25 & 3 & 0 \\
\hline Goiandira & $\begin{array}{l}\text { 31. Escola Estadual Amelia de } \\
\text { Castro Lima }\end{array}$ & 15 & 4 & 2 \\
\hline Goiandira & $\begin{array}{l}\text { 32. Escola Municipal Santa } \\
\text { Maria Goretti }\end{array}$ & 16 & 4 & 2 \\
\hline Goiandira & $\begin{array}{l}\text { 33. Escola Municipal Santa } \\
\text { Maria Goretti Unidade } 1 \text { - Pré } \\
\text { Escola }\end{array}$ & 8 & 0 & 0 \\
\hline
\end{tabular}


Tabela 1. Levantamento de professores (continuação)

\begin{tabular}{clccc}
\hline Cidade & \multicolumn{1}{c}{ Nome da Instituição } & $\begin{array}{c}\text { Professores } \\
\text { Concursados }\end{array}$ & $\begin{array}{c}\text { Professores } \\
\text { Contratados }\end{array}$ & $\begin{array}{c}\text { Professores } \\
\text { Negros }\end{array}$ \\
\hline Goiandira & $\begin{array}{l}\text { 34. Escola Municipal Santa } \\
\text { Maria Goretti Unidade 2 } \\
\text { Creche }\end{array}$ & 11 & 0 & 2 \\
Nova Aurora & $\begin{array}{l}\text { 35. Colégio Estadual Illydia } \\
\text { Maria Perilo Caiado }\end{array}$ & 10 & 4 & 0 \\
Nova Aurora & $\begin{array}{l}\text { 36. Escola Estadual Raimundo } \\
\text { Gomide } \\
\text { 37. Escola Municipal Jardim de }\end{array}$ & 7 & 2 & 0 \\
Nova Aurora & $\begin{array}{l}\text { Infância Branca de Neve } \\
\text { 38. Colégio Estadual Antônio }\end{array}$ & 12 & 13 & 0 \\
Ouvidor & $\begin{array}{l}\text { Ferreira Goulart } \\
\text { 39. Escola Estadual Dacio }\end{array}$ & 6 & 7 & 1 \\
Omorim Fonseca & $\begin{array}{l}\text { Amidor Secretaria Municipal de } \\
\text { Educação - Ouvidor } \\
\text { 41. Colégio Estadual Maria Elias } \\
\text { de Melo }\end{array}$ & 16 & 5 & 0 \\
\hline Três Ranchos & 28 & 10 & 0 \\
\hline
\end{tabular}

A Tabela 1 evidencia o quão baixo é o número de professores negros na região do sudeste goiano, considerando-se os números absolutos alcançados pela pesquisa de campo, de forma que a presente pesquisa nos leva a refletir sobre a necessidade da ampliação de discussões que busquem o significado dos dados acima. Como aponta Patrícia Santana,

Se analisarmos o conjunto dos relatos dos professores negros sobre a escola e a postura de alguns profissionais, veremos que não é questão de desconhecimento, de desinformação, de ausência de formação. É possível pensar que existe algo que vai além da questão de não terem passado por processos formativos que os habilitassem a ter outro tipo de postura. A crueza dos relatos demonstra que mais uma vez o preconceito prevaleceu, e continua realizando estragos e mantendo o status quo de determinados grupos. Apesar das ambiguidades na forma de como esse racismo se expressa, se levarmos em consideração que a maioria dos professores dessa escola são brancos, essa situação teria que ser levada mais a sério, como um quadro de conflito racial (SANTANA, 2004, p. 125-126).

O que se percebe, então é a importância de nosso estudo para o conhecimento da situação verificada em nossa região e como isso responde às questões ante- 
riormente colocadas sobre a dificuldade de as populações negras se integrarem em determinadas áreas da sociedade, como a educação.

Para além dos dados coletados, também é preciso fazer um breve relato de fatos ocorridos no desenrolar das visitas às instituições de ensino. Comecemos pelo município de Anhanguera, onde fomos extremamente bem recebidos. Em uma das escolas, fomos recepcionados por uma das coordenadoras, que se diz negra. Solicitei a ela as informações necessárias para o desenvolvimento da pesquisa e, antes mesmo de responder e após olhar as questões, ela ressaltou que é difícil ser professor negro, aliás, que é difícil ser negro em qualquer profissão. Isso foi dito com voz trêmula e tristeza no olhar e, dobrando um papel que estava em suas mãos, constantemente a coordenadora abaixava a cabeça e fazia alguns minutos de silêncio, silêncio este que dizia mais do que muitas palavras.

Em contrapartida, ao indagar se ela poderia ser nossa entrevistada, a coordenadora recuou e se negou, dizendo que sua atuação é muito tranquila naquela escola, que nunca enfrentou obstáculos raciais por sempre trabalhar em cidade pequena, e que, vivendo uma realidade tranquila nesse sentido, não se fala sobre racismo naquele ambiente. Como mencionamos acima, trata-se do racismo silencioso, velado, e que mais se propala na sociedade, pois é muito fácil ignorar o problema, como se ele não existisse. Isso já nos aponta como é difícil para a pesquisadora, também negra, compreender como se dá esse imaginário que cerca o ser negro na escola. No decorrer dessa conversa informal, a professora diz que às vezes o racismo na escola é velado e que as pessoas fingem que não existe (embora ela mesma tenha anteriormente negado a existência desse racismo), afirma que a escola pública é para o negro e, consequentemente, que os negros estão na escola pública. Ainda, fala que muitas vezes foi indagada pela sociedade do seu município de como conseguiu ingressar ao ensino superior, apesar de reiterar que, por ser Anhanguera uma cidade pequena, não se fala tanto em racismo, e relembra que, ao ingressar na pós-graduação, seu professor a indagou se ela chegou a este patamar por pura teimosia, pois, sendo negra deficiente e de escola pública, a pós-graduação não era o seu lugar, estando ela lá por pura persistência. Naquele momento, a professora diz que não abaixou a cabeça nem se sentiu inferiorizada, e com um sorriso no rosto, respondeu que era teimosa sim, e que continuaria até o fim. Sobre o ser negro a partir das experiências entendidas pelo próprio negro, Lee Anne Bell (2003) afirma que:

As pessoas de cor mais frequentemente entendem sua experiência através de uma consciência de discriminação passada e contínua que afeta todo aspecto de suas vidas nesta sociedade. As pessoas veem a história se repetindo continuamente através da oscilação de ciclos de progresso e retirada em assuntos raciais (BELL, 2003, p. 4).

Diante disso, é preciso compreender como os professores - e, no caso de Anhanguera, a professora que nos recebeu - reagem à uma pesquisa sobre negros 
e racismo, visto que a professora nos diz que não se coloca na condição de vítima e, ainda, diz que há muitos negros que não se aceitam e ela mesma conhece diversas pessoas que vivem essa negação, como a tia da pesquisadora. Por fim, a professora diz que jamais se casaria com um negro porque não queria que os filhos tivessem traços negros, e por isso se casou com um branco, escolha que ela justifica por ter sido ensinada pelos seus antepassados que negro "faz mal feito" e que negro não tem condições sociais, reproduzindo esse discurso racista que a ela foi ensinado.

Nos lares de famílias negras e na escola, a maneira mais comum de se lidar com o preconceito é o silêncio. [...] Parece ser politicamente correto tratar o afrodescendente como moreno, palavra fortemente enraizada na cultura brasileira. É um exemplo de uma situação que revela uma estratégia simbólica de fuga de uma realidade em que a discriminação impera. Dessa forma as pessoas procuram elementos de identificação em símbolos do grupo considerado social e economicamente dominante, no caso o brasileiro branco-europeu (FERREIRA, 2002, p. 72).

Podemos observar que, na conversa com essa professora, esta, a princípio, se negou a falar do assunto e, com segurança, dizia que não havia racismo ali, mas no decorrer da conversa ela mesma foi reconhecendo a presença do racismo e, no fim, ainda pontuou que isso acontece de forma velada, dizendo que passou por algumas situações difíceis e constrangedoras de racismo em sala de aula; mas, novamente se cala e afirma que prefere não falar sobre o assunto - como menciona Ferreira, "assim não temos de compreender o que não existe" (FERREIRA 2002, p. 70). Percebe-se uma confusão de sentimentos dentro dela, de não conseguir se expressar sem sentir a dor de um racismo sempre presente, por vezes tentando se refugiar na farsa de uma democracia racial para fugir da dor que é a realidade.

Sobretudo, é perceptível que esses são alguns dos discursos construídos ao longo das relações tecidas no seio familiar, escolar e social. Assim, tem-se um dia a dia marcado por discriminações, agravado por discursos midiáticos que, na maioria das vezes, inferiorizam a mulher negra, que acaba sendo vista como objeto sexual e motivo de cobiça, dentre outros estereótipos. Esses discursos por vezes aparecem embutidos no mascaramento e no silêncio, que, como resultado, geram o ressentimento, mas nunca o esquecimento ou o apagamento dessa realidade. O problema mais evidente nessa conversa foi o fato de ainda não ter por certo o que é ser uma mulher negra, e é isso que a dúvida e o silêncio dizem. $\mathrm{O}$ que se sabe sobre ser mulher negra é o que ouvem outras pessoas falarem sobre si mesmas. Ferreira (2002, p. 75) diz que, "em função do processo de desvalorização da pessoa negra, os afrodescendentes tendem a interiorizar a visão dominante do mundo branco visto como superior. Em decorrência, tendem a desvalorizar o 
mundo negro ou assumirem como insignificante para suas vidas o fato de serem afrodescendentes".

A coordenadora de outra escola no município de Anhanguera pontua que é comum os negros se dizerem pardos, e depois se dizem e intitulam negros, ainda ressalta que mesmo com tantos problemas hoje em dia o cara pode ser azul, que ainda diz ser pardo, ninguém quer ser negro. Vê-se, então, alguns processos envolvidos na construção da identidade do brasileiro afrodescendente.

Já a coordenadora da creche do município de Anhanguera (branca), ao pegar o questionário, indaga se ainda existe racismo, pontuando que antigamente isso era verdade, mas que hoje todos são iguais, e conclui dizendo que naquela escola não há esse tipo de preconceito, exemplificando que uma funcionária responsável pela limpeza é negra. Disse, ainda, que foi em um congresso sobre diversidade e a mesa era composta só por negros (com espanto) e que só se falava "sobre isso", sobre racismo (com indiferença). A dureza com que essa senhora nos diz essas palavras parece reverberar a nossa própria experiência de vida, e isso é de nossa sociedade. Conforme Ferreira,

Tais questões sugerem a dificuldade de se lidar no Brasil com o preconceito racial. Este revela-se no dia a dia, nas situações mais simples. Numa sociedade em que, apesar da crença consolidada de ser o país da democracia racial, as pessoas desenvolvem um mundo simbólico, cujas características fenotípicas acabam operando como referências para o preconceito. (FERREIRA, 2002, p. 72)

Em Cumari, ouvimos da diretora que, na cidade não havia professores negros, afirmando que "na cidade tem uma professora da minha cor", mas reforça que ela não é negra por ter "cabelo bom e liso" - ou seja, "ela é da minha cor mas tem o cabelo bom, então não é negra, ela é morena, bem moreninha". Ferreira (2002, p. 76) externa sua visão sobre esse assunto e diz que "as noções de beleza são derivadas de uma estética 'branca' usada como referência correta, positiva racional e bem desenvolvida, levando em decorrência a uma desvalorização da estética negra, encarada como exótica, emocional e primitiva, qualidades consideradas menores".

O que podemos perceber com as afirmações da professora é a inferiorização dos traços negros, de forma que o indivíduo tem a sensação de não pertencer realmente a nenhum grupo, pois dentro dele estão internalizados valores "brancos" e o fato de ser negro gera um sentimento de desvalorização enquanto pessoa.

Catalão foi o município no qual fui, de forma clara, mais maltratada na realização do trabalho de campo. Às vezes com muito descaso nos respondiam às questões solicitadas, outrora diziam que não teriam tempo para isso - $\mathrm{o}$ interessante é que, via e-mail, as respostas eram gentis, mas no ato de recolha das 
informações pessoalmente, o tratamento era outro, indiferente e frio. $\mathrm{O}$ primeiro ponto de partida foi ir à Subsecretaria de Ensino na Regional Catalão, que alegou não ter as informações sobre os professores negros, que é um assunto que não vem ao caso e é indelicado falar disso. Diante disso, fui pessoalmente às escolas em busca dessas informações. Mas, como mencionado acima, o tratamento não foi dos melhores. Conseguir os dados expostos na Tabela 1 foi um trabalho árduo.

Em uma das escolas foi especialmente notória a resistência em ceder as informações necessárias à pesquisa em função de a entrevistadora ser negra. Quando cheguei nesta instituição, fui recebida com grosseria, a secretária mal me olhou ao responder às questões e quando indaguei a quantidade de professores negros na escola, a mesma imediatamente se exasperou e, irritada, me olhou e disse que não queria falar sobre esse assunto, que "isso não é pergunta que se faça”, e que ela não sabia "disso", sendo incapaz de me informar quem era negro ou não. A este respeito, Gomes (1994) diz que:

O Racismo e a discriminação racial, que fazem parte da sociedade brasileira, estão presentes na escola, na relação entre os educadores e entre professores e alunos. $\mathrm{O}$ próprio fato de não se aceitar que nas escolas existam racismo e discriminação racial pode ser considerado como um indicador de sua existência. Negar a existência do outro já é a confirmação da sua presença (GOMES, 1994. p. 51).

No contato com as escolas visitadas, pude notar muitas funcionárias responsáveis pela limpeza e pela segurança que eram negras, mas, como os dados da Tabela 1 evidenciam, professores negros eram a minoria ou nem sequer existiam.

Para concluir, como aponta Gomes (1994), vale ressaltar que o professor negro visto como sujeito é portador de valores culturais que refletem suas representações sobre o que é ser negro na sociedade brasileira. Portanto, não podemos negligenciar que a escola ainda é uma das instituições sociais que, por sua vez, interferem significativamente no processo da construção da identidade racial tanto de professores quanto de alunos negros. Então, de certa forma, o silenciamento, a folclorização da cultura e a ênfase e o crédito dados à teoria da "democracia racial" são fatores que impedem a ampliação da discussão sobre relações raciais nas escolas. Às vezes, o silêncio e a omissão são impedimentos cruciais para essa problemática gritante.

Os resultados da pesquisa ainda são parciais, pois faltam os dados de algumas cidades para a conclusão do trabalho de campo. Até aqui, percebemos que ser professor negro nesse país ainda significa ter que transpor diversas barreiras, visto que ter uma formação universitária em uma sociedade onde o negro historicamente tem baixa escolaridade ainda é um grande desafio a ser enfrentado, e ser aceito em uma comunidade escolar exige transformação cultural. 


\section{PROPOSTA FINAL: PROFESSORES NEGROS, ONDE ESTÃO? CAMINHOS INVESTIGATIVOS ENTRE A MEMÓRIA E A HISTÓRIA}

\section{(...) que memória conserva o indivíduo de seus próprios ressentimentos?}

(Pierre Ansart)

Em nossa discussão final, propomos o questionamento dos dados coletados expostos no item anterior e a elaboração da descrição densa das entrevistas com os professores do sudeste goiano, problematizando sua experiência escolar, os contextos político-sociais, suas experiências com a discriminação racial e seus questionamentos pessoais. Será entrevistado um professor de cada cidade do sudeste goiano, abordando-se os seguintes temas: vida, família, infância, experiência como professor, trajetórias e espaços de atuação profissional em seu percurso enquanto professor negro. Então, serão transcritas as entrevistas, evidenciando os contextos escolares e as relações raciais na escola enquanto espaço de manifestação de discriminação racial. Por fim, serão abordadas as políticas públicas relativas à questão. Trabalharemos tanto com histórias de vidas individuais, quanto com histórias de vida observadas em nossa própria experiência, coletadas com entrevistas e testemunhos, mas ainda dependemos do parecer do Comitê de Ética da UFG para realização dessa fase da pesquisa.

A conclusão possível até agora nessa discussão é a de que não vivemos em um país livre do racismo, do preconceito e da discriminação, mas, ao contrário, vivemos em um país cuja cultura criou representações tão arraigadas sobre o ser negro ou negra, que perpetua tais representações não apenas em espaços formais do pensamento, como a escola, mas também, como se demonstrou, em práticas informais. $\mathrm{O}$ resultado esperado com a pesquisa é contribuir com a discussão sobre racismo, preconceito e a vida dos professores negros no sudeste goiano, promovendo conscientização tanto com a dissertação quanto com as oficinas de ensino que serão realizadas.

\section{REFERÊNCIAS}

ALBERTI, V. História oral: a experiência do CPDOC. RJ:CPDOC, 1989.

ANDREWS, G. R. Negros e brancos em São Paulo (1888-1988). Bauru: EDUSC, 1998.

BAIA HORTA, J. S. O hino, o sermão e a ordem do dia. Rio de Janeiro: Ed. UFRJ, 1994.

BELL, L. A. Contando contos: o que as histórias podem nos ensinar sobre o racismo.

Etnia raça e a Educação, v. 6, n. 1, p. 3-28, 2003. 
BITTENCOURT, C. Pátria, civilização e trabalho. São Paulo: Loyola, 1990.

$\mathrm{BLOCH}, \mathrm{M}$. Apologia da História: ou o ofício do historiador. Rio de Janeiro: Jorge Zahar, 2001.

CHALOUB, S. Cidade febril: cortiços e epidemias na corte imperial. São Paulo: Companhia das Letras, 2011.

CHARTIER, R. História Cultural: entre práticas e representações. Lisboa/Rio de Janeiro: Difel/Bertrand do Brasil, 1988.

D’ÁVILA, J. Diploma de brancura. São Paulo: Ed. Unesp, 2005.5.

DUARTE, R. Pesquisa qualitativa: reflexões sobre o trabalho de campo. Cadernos de Pesquisa, n. 115, p. 139-154, mar. 2002.

FERNANDES, F. A integração do negro na sociedade de classes. Dominus Editora, São Paulo 1965. FOLHA On-line. Disponível em: <http://www1.folha.uol.com.br/folha/ dinheiro/ult91u112473.Shtml>. Acesso em: 20 nov. 2006.

FILHO, G. R.; PERÓN, C. M. R. (Org.). Racismo e educação: contribuições para a implementação da lei 10639/03. Uberlândia, EDUFU, 2011.

FERREIRA, R. F. O brasileiro, o racismo silencioso e a emancipação do afrodescendente. Psicologia \& Sociedade. n. 14(1), p. 69-86, jan/jun. 2002.

FREYRE, G. Casa grande e senzala. Rio de Janeiro: Schmidt Editor, 1993.

GOMES, N. L. Professoras negras: identidades e memória. Educ. Rev, Belo Horizonte (18/19), p. 49-58, dez. 1993/jun. 1994.

GUIMARÃES, Geni. A cor da ternura. São Paulo: FTD, 1998.

HASENBALG, C.; SILVA, N. do V. (Org.). Estrutura social, mobilidade e raça. Rio de Janeiro: Iuperj/Vértice, 1988.

LE GOFF, J. História e Memória. Campinas, SP: Editora da Unicamp, 1990.

PESAVENTO, S. J. História \& história cultural. 2 ed. Belo Horizonte: Autêntica, 2004.

RIBEIRO, M. S. O romper do silêncio: história e memória na trajetória escolar e profissional dos docentes afrodescendentes das universidades públicas do estado de São Paulo. 2012. Disponível em: <http://w3.ufsm.br/afirme/LEITURA/noensino/ne04.pdf>. Acesso em: 30 out. 2012.

SANTANA, P. Professores Negros. Belo Horizonte: Mazza Edições. 2004

SCHWARCZ, L. M. O espetáculo das raças: cientistas, instituições e a questão racial no Brasil (1870-1930). São Paulo: Companhia das Letras, 1993. 